\title{
System analysis for integration of landfill energy production in regional energy supply
}

\author{
G. Kuplais, D. Blumberga \& E. Dace \\ Institute of Energy Systems and Environment, \\ Riga Technical University, Latvia
}

\begin{abstract}
The waste management solutions in landfills of Latvia differ. Some of them are developed according to the concept of biogas production and use in power plants or cogeneration plants (CHP). The use of biogas in CHP depends on energy consumption and supply, and availability of energy consumers. More often are cases when there are no possibilities to connect heat energy consumers, which create problems of the low energy efficiency of power plants' operation.

A structure of energy user in Latvia is characterized by high energy consumption in households, public and service sector, compared with relatively low consumption in the rural and industrial sector. This situation obligates special tasks for power sector development, especially choosing energy resources to ensure energy production and supply. In Latvia imported fossil and renewable energy resources are used. A use of specific energy resource depends on an energy supply policy, and total consumption of energy resources depends on the development of every type of energy resources in regions. Now there is an unjustified high proportion of fossil fuel in state energy balance which it is possible to reduce by beginning the active use of local fuel in regions.

$\mathrm{RDF}$ and landfill gas as a renewable energy source could play a role in the development of local energy resources in Latvia, which should be based on principles of cluster, integration and gradualness. In this paper the main attention is paid to waste management problems from the development of a regional power supply system point of view together with understanding, that those are not two separate systems, but two parts of one system with dynamic rather than static development.
\end{abstract}

Keywords: biogas, landfill gas, refuse derived fuel, regional energy supply, renewable energy sources, system analysis. 


\section{Introduction}

Centralization of waste dumps was considered to be the main task of waste management system of Latvia at the end of 1990s and the beginning of this century, therefore a policy, where 500 small scale dumps were supposed to be replaced by 11 big scale landfill sites, was enforced. At that time an idea of large landfill site depositories, where biogas is produced by decomposing organic waste, was implemented in the policy. There were biogas collecting systems developed and established. In regions this conception gave opportunity to produce energy from biogas.

Problems began when biogas utilization in cogeneration plants (CHP) was encumbered with no possibilities to find heat energy consumers, which in turn resulted with low efficiency landfill power plants almost all over Latvia. The emerging situation forced one to look for another solution related to biogas utilization in providing the other needs of consumers.

Due to high electricity feed in there is an economical motivation for power plant operation with low efficiency. For electricity produced in renewable energy power plants with a nominal capacity of up to $4 \mathrm{MW}$ high feed in tariff has been transposed in Latvia's legislative acts.

Now, because of the above mentioned reasons, development of Latvia's landfill sites is at the crossroads. On one hand it is economically feasible to operate CHP just for electricity production, but on the other - it is important to use natural resources on full value by producing from biogas the maximum amount of heat energy. In first case it means that there is no need for waste sorting in landfills, but in the other it is important to sort both - before waste collection and in landfills.

In this paper the main attention is paid to waste management problems from the development of regional power supply system point of view together with understanding that those are not two separate systems, but two parts of one system with dynamic rather than static development.

In this paper, analysis of the system is made base on the operational study of one of Latvia's landfills - landfill "Daibe".

\section{Energy production from waste}

If to take into account that waste is any substance which the holder discards or intends or is required to discard [1], municipal solid waste is a waste type that includes predominantly household waste with sometimes the addition of commercial wastes collected by a municipality within a given area. Municipal solid waste landfill sites are a large source of human-related methane emissions, therefore if it is not dealt with in a sustainable manner; it can contribute to greenhouse gas emissions and, by implication, climate change.

Latvia has been divided into 11 waste management regions for industrial and municipal waste of which North Vidzeme Region is the second largest by population (see Fig.1). In 2004 municipal waste landfill "Daibe" was put into 


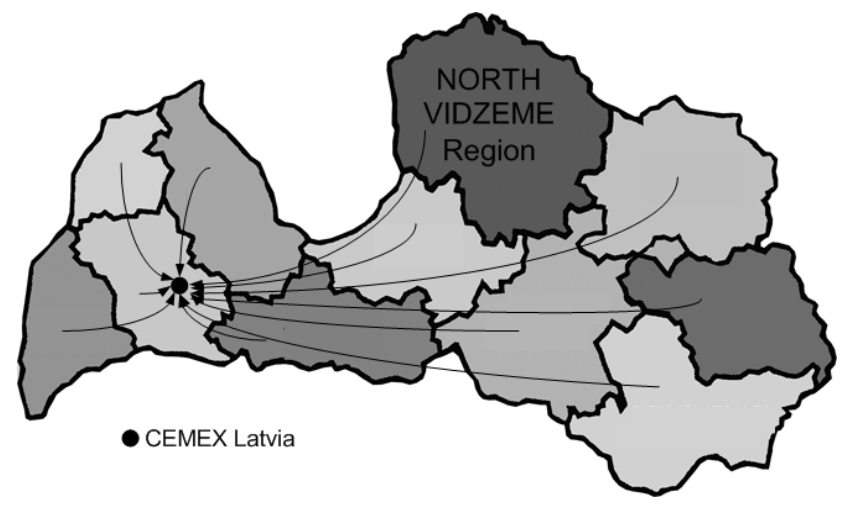

Figure 1: Waste management regions in Latvia with potential distribution of the refuse derived fuel (RDF).

operation, and since then is the place for treatment and depositing solid municipal waste in North Vidzeme Region.

It is obvious that many waste streams are not subject to direct processing and will require special measures in the form of specific pretreatment of the waste prior to processing (see Fig. 2). One form of pretreatment is separation and recycling of waste components thereby removing a portion of the waste stream for recycling and other uses (Speight [2]).

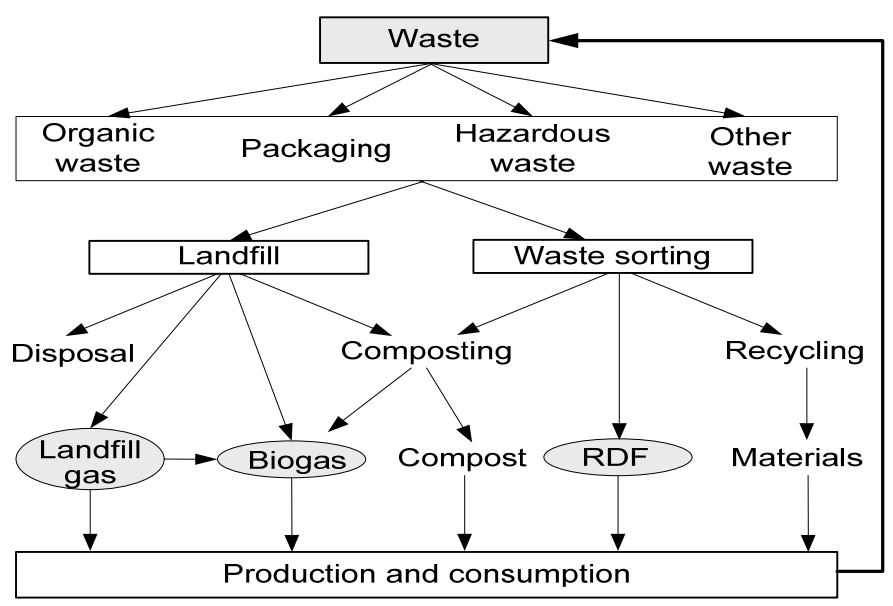

Figure 2: Waste stream processing options.

Municipal and industrial waste could provide feedstock for a number of conversion systems, all of which could recover useful energy while reducing the requirement for landfill sites.

In Latvia the potential of energy efficient utilization of landfills' energy sources is related to waste sorting and RDF production, as well as to organic 
waste composting with biogas production, and utilization and recycling in landfill.

\section{Landfill gas}

Instead of allowing landfill gas to escape into the air, it can be captured, converted, and used as an energy source for existing landfills. Using landfill gas helps to reduce odors and other hazards associated with landfill gas emissions, and it helps to prevent methane from migrating into the atmosphere and contributing to local smog and global climate change (Barlaz [3]).

Power generation from landfill gas offers major air quality benefits where landfills already exist or where the decision to build the landfill has already been made (Speight [2]).

Composition of the landfill gas varies with age and type of waste. Landfill gas is composed of a mixture of hundreds of different gases. By volume, landfill gas typically contains $45 \%$ to $60 \%$ methane and $40 \%$ to $60 \%$ carbon dioxide. Landfill gas also includes small amounts of other compounds [4].

Figure 3 shows amount of the landfill gas emissions in landfill "Daibe", starting from year 2005 up to 2013 (projection). About 50\% of it can be collected with the existing technology in the landfill. The measurements of the collected landfill gas show average concentration of methane around $60 \%$ in it. The produced landfill gas is incinerated in cogeneration plant (CHP) with efficiency factor of 0.37 . Figure 4 shows the amount of electricity produced in this CHP during 7 month period.

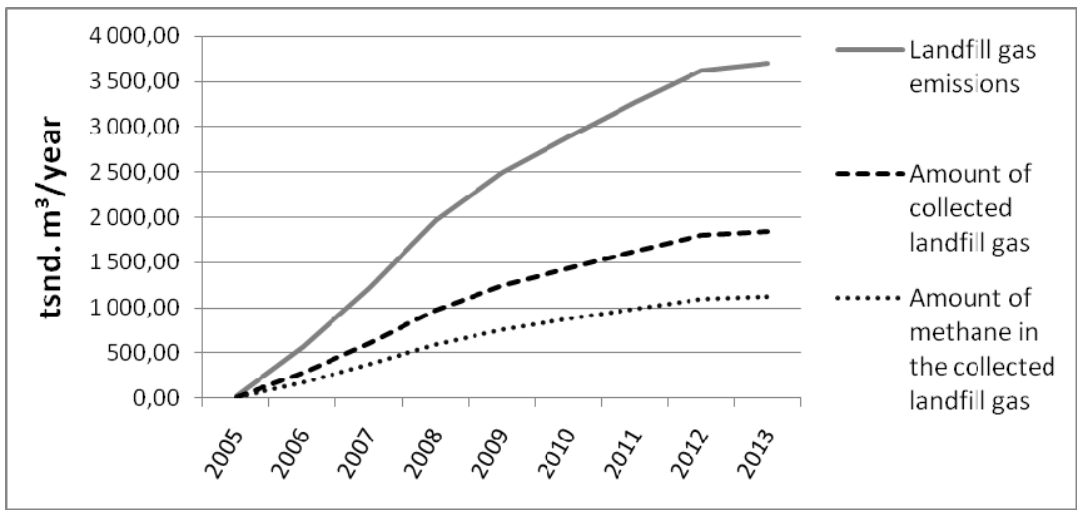

Figure 3: Landfill gas emission and collection parameters in landfill "Daibe".

As it can be seen from the graph in Figure 4, the amount of electricity produced changes very rapidly. Mostly it is dependant on the amount of collected landfill gas, however it may be associated also with methane content in the gas. Another associated problem, which was logged during the CHP opertation period (214 days), is that the CHP stopped for 298 times (!). 


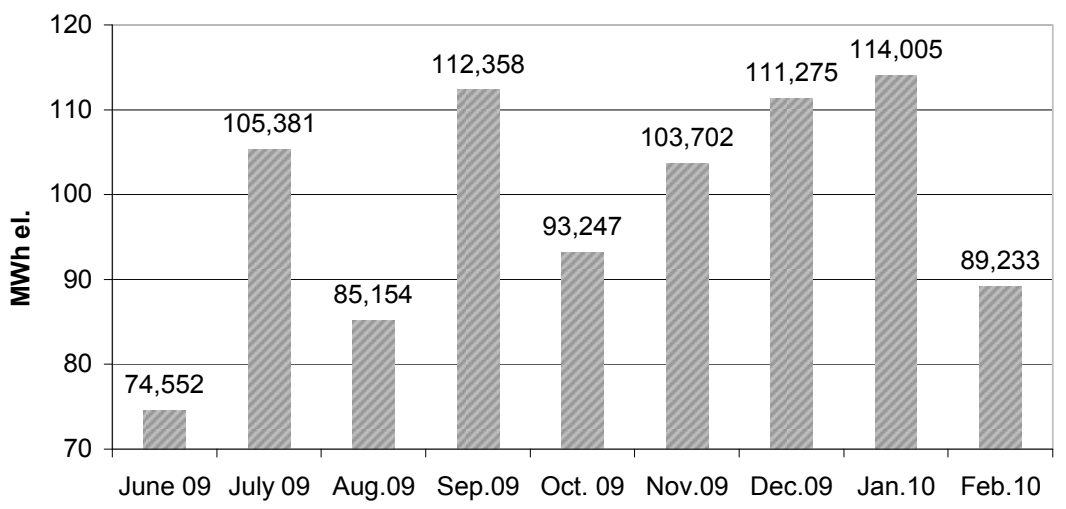

Time period

Figure 4: $\quad$ Electricity produced in CHP of landfill "Daibe".

Since methane content is so low, the production of alternative fuels from landfill gas in landfill "Daibe" is now an emerging area. One of the options is biogas production.

\section{Biogas production and utilization for reconstructed landfills}

Biogas from landfills as a renewable energy source could play role in development of local energy resource in Latvia, which should be based on principles of cluster, integration and gradualness. The first principle is based on situation when regions with landfills select development of its own energy sector, integrating development plan of energy supply system into territorial plan of area or city. By use of integration principle (including biogas from landfills) it is possible to forecast total development of state power and energy sector, taking down regional limits of energy supply. The renewable energy grid should be established for use of biogas from landfills, streams of wood, straw and other biomass in energy sector of Latvia.

Some of the waste management solutions in landfills of Latvia are developed according to concept of low grade biogas (landfill gas) production and use in power plants or CHPs. Use of biogas in CHP depends from energy consumption and supply and availability of energy consumers. More often are cases when there are no possibilities to connect heat energy consumers, which create problems of low energy efficiency of power plants' operation.

Another alternative biogas utilization options are injection into natural gas grid or transport fueling.

For the use of biogas as transport fuel or its injection into a natural gas grid the only suitable fraction in biogas is methane. Other its components (carbon dioxide, hydrogen sulphide, hydrogen, etc.) are unsuitable for these purposes, undesirable or even hazardous; therefore, they should be removed from biogas by cleaning and upgrading it (see Fig. 5). 


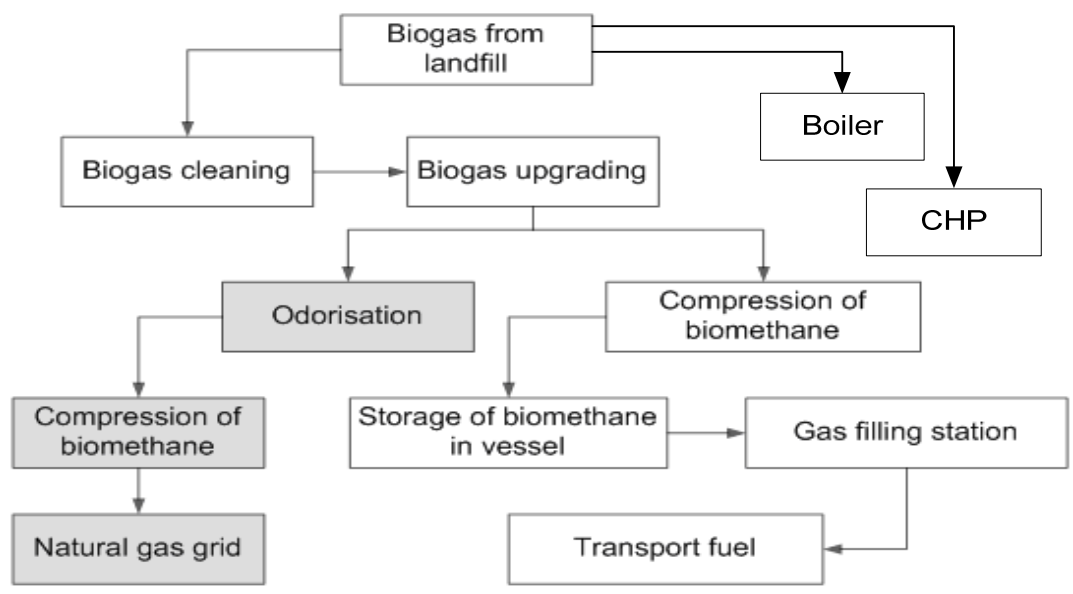

Figure 5: $\quad$ Stages of upgrading the biomass quality.

Cleaning process involves separation of the cumbersome compounds from biogas as well as water vapor separation or biogas moisture content reduction. Upgrading of biogas is cleaning process when the ballast is drained from it; thereby the methane content of biogas is increased. Methane concentration of landfill gas which is usually $45-60 \%$ is increased over $95 \%$. To reach necessary Wobbe index of gas, carbon dioxide has to be removed.

Requirements which have to be fulfilled for biogas injection into natural gas grid: specific odors used in natural gas system have to be added to biogas (process of odorisation), and the pressure has to be increased to match with a pressure in respective section of natural gas grid.

For biogas use in vehicles, storage and filling system, which ensures effective biogas supply to vehicles, has to be developed.

The landfill "Daibe" is considering the option of upgrading the biogas for its utilization as a transportation fuel. Option of injecting the biogas into natural gas grid is not deliberated for now because of existing barriers, such as high quality requirements for biogas, large investments and lack of state's regulatory normative acts.

\section{RDF}

One form of materials recycling is the refuse derived fuel (RDF) - form of the combustible fraction of municipal solid waste. In order to produce such a fuel, RDF plant seeks to concentrate the combustible fraction of the waste by removal of non-combustible materials, such as glass and metals. Conversion of municipal solid waste to RDF depends on the type of process used to produce the RDF; the conversion rate can vary between 23 and $50 \%$ by weight. The raw waste has a typical calorific value of $9.1 \mathrm{MJ} / \mathrm{kg}$ whilst the processed coarse RDF has a calorific value of approximately $18.0 \mathrm{MJ} / \mathrm{kg}$ (Williams [5]). 
The combustion of RDF in cement kilns is a significant route of energy recovery utilization. In case of sorting of waste by production of RDF in Latvia, utilization as energy source will be possible in a cement kiln. CEMEX Latvia the only cement kiln in Latvia and the largest one in the Baltic States, is ready to use RDF for supplying their production processes with energy. It is estimated that to cover all their production needs with RDF, three times as much waste would be needed as it is in Latvia. It means that even by using all of Latvia's waste for RDF production, it would not be enough to supply CEMEX Latvia.

\section{System dynamics analyses}

All above mentioned indicates that development and major role of landfills in energy supply system of Latvia's regions is dependant on various factors, like waste management parameters (waste sorting grade in landfills and before their transportation to landfills, level of waste recycling etc.), economical factors (waste transportation costs, natural resource tax, energy resource costs, energy production and feed in tariffs, development and costs of biogas upgrading methods etc.), impact on decrease of global climate change (decrease of landfill gas losses from depositories, decrease of greenhouse gases, decomposition of organic substances and biogas production in special landfill bioreactors etc.) a.o.

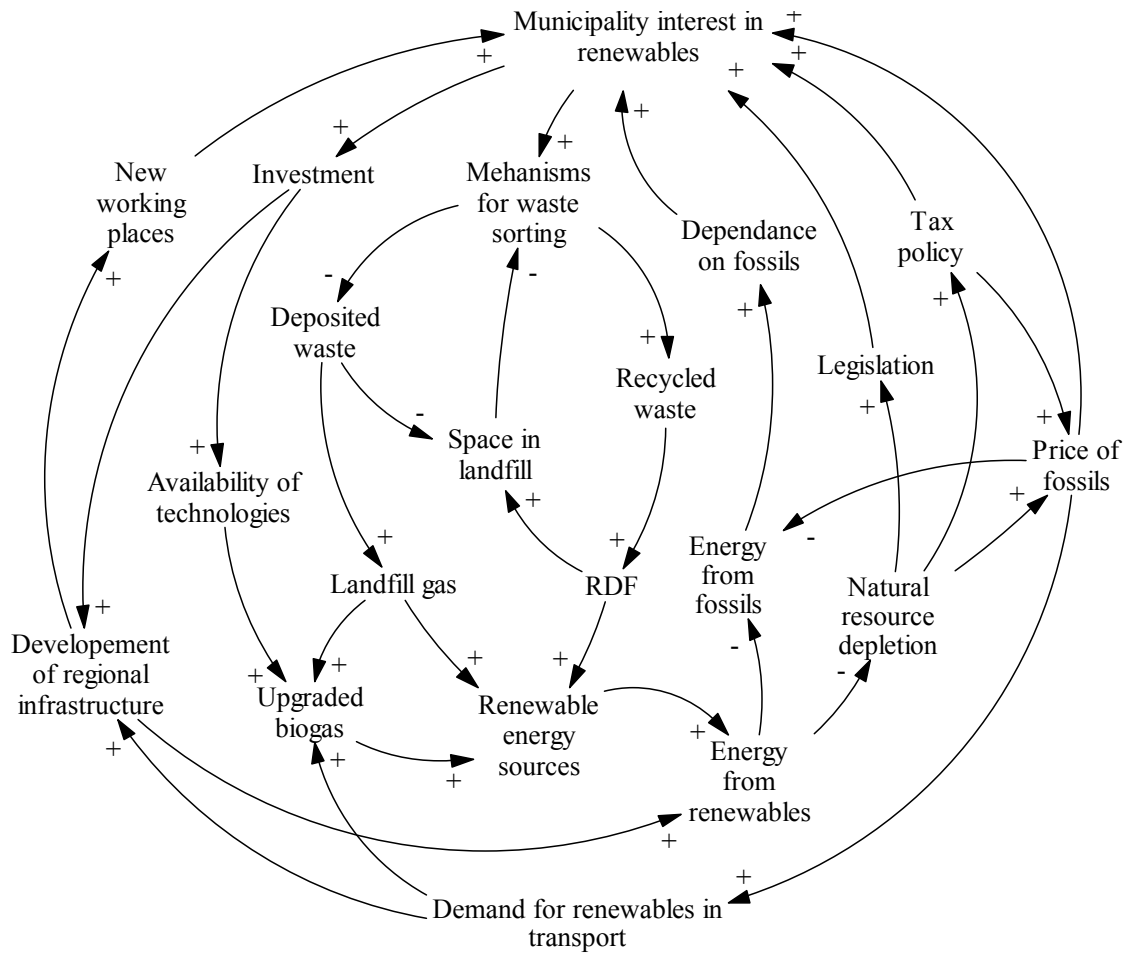

Figure 6: Causal loops' diagram of system dynamics analyses. 
System dynamics is a modelling methodology, which permits an analyst to represent graphically and mathematically the interactions governing the dynamic behavior of complex socio-economic systems (Vizayakumar [6]). The purpose of a system dynamics intervention is to identify how structure and decision policies generate system behavior identified as problematic, so that structural and policy oriented solutions can be identified and implemented (Saleh et.al. [7]).

The analysis of impact of the above mentioned factors is possible by using system dynamics model, the exaple of which is illustrated in Figure 6.

The diagram shows that energy produced from renewable energy sources will rise only when interest of municipalities in such an energy will increse. That can happen when renewables promoting legislative acts or taxation policy is in force, as well as growth of dependance on fossil fuels and their price. When that happens, municipalities develop mechanisms and technologies for renewables by investing finansial resources.

Decrease of acumulated waste amount in landfill "Daibe" by energy production and integration in the regional energy supply has been analyzed, basing on various aspects and using the existing and projected data.

\section{Results}

The system is analyzed in 10 year time period - from year 2003 up to year 2013 (projection). Such a time range has been chosen because of accessibility of both - the past and the projected data.
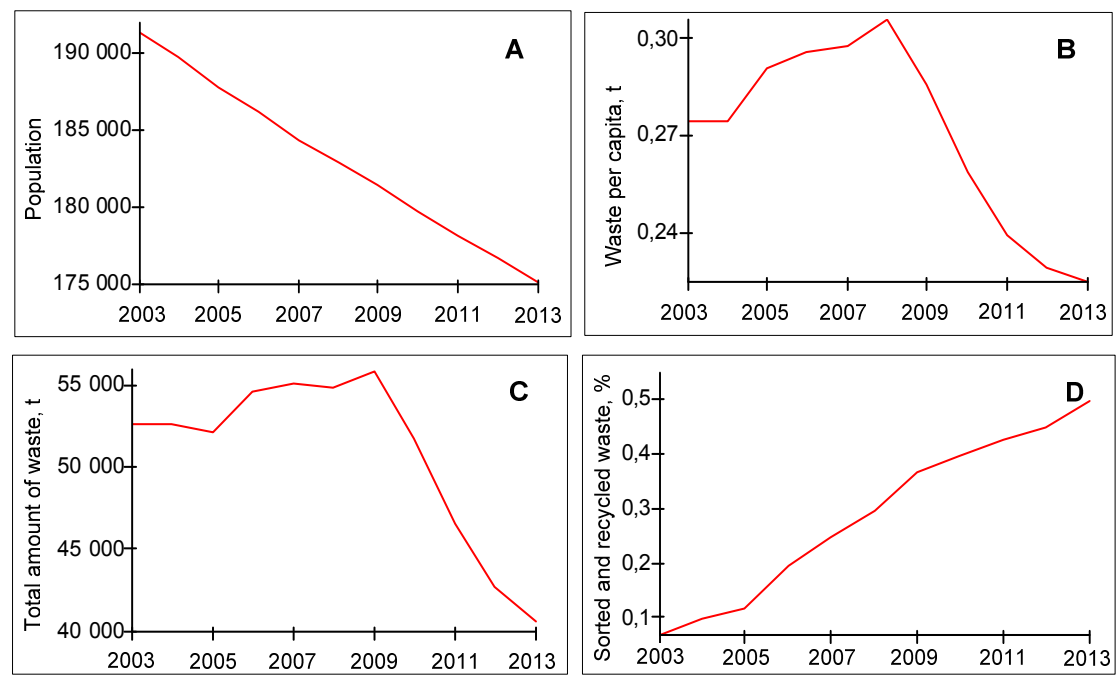

Figure 7: Graphs characterizing North Vidzeme Region in the aspect of waste production: A - Resident population in the region; $\mathrm{B}$ - Amount of waste produced per capita; C - Total amount of waste produced in the region; D - percentage of sorted and recycled waste amount. 
Figure 7 shows the resident population and the amount of waste produced per capita in North Vidzeme Region, as well as the total waste amount produced and the percentage of sorted and recycled waste amount out of it in the region.

It can be seen from the graphs that population is decreasing linearly, whereas the amount of waste produced per capita raises at the beginning, but afterwards decreases quite rapidly. It can be explained by rapid GDP decrease in the state due to global economical crisis, which has hit Latvia quite strong.

The parameters showed in Figure 7 are relevant to estimate the amount of waste that could reach the landfill. Landfill gas or RDF can be produced from this waste for utilization in energy production. If to assume that all the combustible fraction of waste is removed to produce RDF, which is used for energy production in cement kiln of CEMEX Latvia, than only the noncombustible and non-recyclable fraction is deposited in the landfill. In landfill "Daibe" up to $40 \%$ of the introduced waste could be considered as noncombustible and non-recyclable fraction. The rest may be used for RDF production.

Dynamics of waste accumulation in the landfill "Daibe" can be drawn by modeling the implementation of waste sorting for the production of RDF. Figure 8 shows comparison of the waste accumulation dynamics, if RDF production is implemented this year already and if it is not implemented at all.

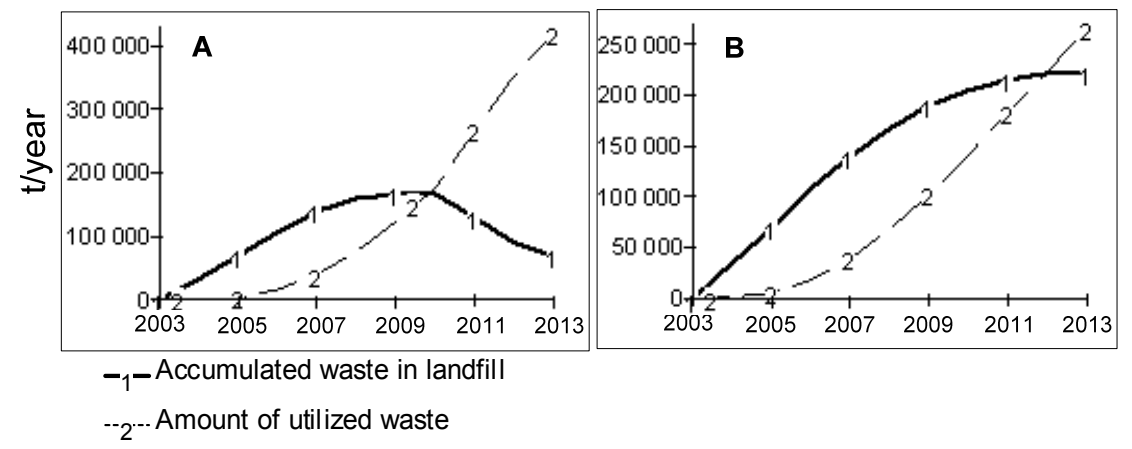

Figure 8: The dynamics of waste accumulation and utilization in the landfill "Daibe": A - RDF production is implemented this year; B - RDF production is not implemented at all.

In Figure 8 the graph A shows that the amount of accumulated waste drops rapidly, when waste utilization for RDF production is introduced. If the current system is not changed, it is, the waste is accumulated and only the landfill gas is collected, then the dynamics of waste accumulation looks like the one in graph B - it shows goal-seeking tendency of waste accumulation, and besides that the amount of accumulated waste in 2013 is about $65 \%$ more than in case of RDF production.

System analysis shows that there is a great potential for waste utilization in energy production if municipalities are interested in it and if there is enough 
motivation for it, like legislative acts promoting renewable resource utilization or interest from consumer side. The most promising way to decrease deposited waste in landfill is modeled to be RDF production.

\section{Conclusions}

1. Waste landfill sites have high RDF potential, which lets its concentrating in cement kiln. In Latvia it is a future solution.

2. System dynamics analysis allows predicting impact of different factors on waste management and regional energy system of Latvia showing that they have to be considered as one.

3. The example of system dynamics analysis of landfill "Daibe" shows that amount of deposited waste can be decreased by implementing RDF production. If it is done this year already, than by year 2013 the amount of deposited waste is decreased by $65 \%$ comparing with the future projections of the existing waste management system.

\section{References}

[1] Directive 2006/12/EC of the European Parliament and of the Council of 5 April 2006 on waste // Official Journal of the EU, L 114/9 (27.4.2006.)

[2] Speight, J., Synthetic Fuels Handbook, McGraw-Hill: New York, pp. 323365, 2008.

[3] Barlaz, M.A. \& Ham, R.K., Leachate and Gas Generation (Chapter 6), Geotechnical Practice for Waste Disposal, ed. D.E. Daniel, Chapman and Hall: London, pp. 113-136, 1993.

[4] Landfill gas basics, Landfill Gas Primer, An Overview for Environmental Health Professionals, Department of Health and Human Services, Agency for Toxic Substances and Disease Registry, Division of Health Assessment and Consultation, pp. 3 - 12, November 2001.

[5] Williams, P.T., Waste treatment and disposal, John Wiley and Sons: Hoboken, pp. 127-171, 2005.

[6] Vizayakumar, K., Environmental policy analysis: System dynamics approach (Chapter 20), V.K. Agnihotri, Public policy analysis and design, Concept Publishing Company: New Dehli, pp. 311-329, 1995.

[7] Saleh, M., Oliva, R., Kampmann, C.E. \& Davidsen, P.I., A comprehensive analytical approach for policy analysis of system dynamics models, European Journal of Operational Research, Volume 203, pp. 673-683, 2010. 